\title{
FACTORS AFFECTING WORK MOTIVATION OF OFFICE WORKERS - A STUDY IN HO CHI MINH CITY, VIETNAM
}

\author{
Tran Thi Phuong Thuy*1, Tran Thi Bich Nhung ${ }^{2}$ \\ ${ }^{1}$ University Hochiminh city branch, 15 D5 Street 25 Ward Binh Thanh District, HochiminhCity, 084, \\ Vietnam tranthiphuongthuy.cs2@ftu.edu.vn, (0908934282) \\ ${ }^{2}$ Foreign Trade University Hochiminh city branch, 15 D5 Street 25 Ward Binh Thanh District, \\ HochiminhCity, 084, Vietnam, tranthibichnhung.cs2@ftu.edu.vn, (0938028655)
}

\begin{abstract}
Work motivation is one of the central concerns for many researchers and managers. When employees are motivated to work, they will generally put their best effort in the tasks that are assigned to them. Ho Chi Minh City is Vietnam's economic and financial center. Therefore, the existence and development of businesses in Ho Chi Minh City will have great contribution to the social - economic development of Vietnam. This study aims to identify some factors affecting work motivation of office workers at enterprises in Ho Chi Minh City and suggest some solution to enhance work motivation. To achieve the above purposes, Cronbach's Alpha and Exploratory factor analysis (EFA) are used to test the validity of the scale, linear analysis is used to define the factors that affect work motivation of office worker. The study was conducted in two main phases: preliminary research with the sample size of 50 respondents and official research with the sample size of 330 respondents. The result shows there are seven factors that affect office workers' motivation: (1) relationship with superiors, (2) individual recognition, (3) promotion in organization, (4) wages and welfare policy, (5) work interest, (6) working conditions, (7) personal responsibility. Besides that, to enhance work motivation of them, some solutions such as manager-office worker relationship reinforcement, individual recognition, opportunities for promotion and career development, reasonable welfare policies are also mentioned in this study.
\end{abstract}

\section{Keywords}

Ho Chi Minh City, office workers, Vietnam, work motivation

\section{JEL Classification}

C52

DOI: https://doi.org/10.14311/bit.2018.02.01

Editorial information: journal Business \& IT, ISSN 2570-7434, CreativeCommons license (c) (i) published by CTU in Prague, 2018, http://bit.fsv.cvut.cz/ 


\section{Introduction}

Work motivation is one of the most crucial issues in the field of human resource management because the motivation to work is the desire and willingness to perform the tasks of employees in order to achieve organizations' goals. Once having work motivation, the employees themselves will love the job and always try their best to fulfill their assigned tasks. Therefore, the issues relating to work motivation has received a lot of attention from local and international researchers.

Many different theories trying to explain work motivation as well as related factors have been developed over the years. These include Maslow's Hierarchy of Need (1954), Herzberg's Two-factor Theory (1959), John Stacy Adam's Equity Theory (1863), Victor Vroom's Expectancy Theory (1964), Porter and Lawler's Expectancy Theory (1968) and Alderfer's ERG Theory (1969). On the basis of these theories, researchers proposed factors influencing work motivation based on different subjects and scales.

In Vietnam, there are some studies regarding employee motivation. One of such studies is "Factors affecting the motivation of direct production employees in Vietnam Assembly Corporation (LILAMA)" by Bui Thi Minh Thu and Le Nguyen Doan Khoi (2014). This research analyzed and outlined seven factors that affect the motivation of direct production employees at the company: corporate culture, work, opportunity for training and development, working conditions, wages and welfare regime, relationships with colleagues, relationships with the leaders. In of which, wages and welfare regime with the corporate culture are the most powerful factor. In the research "Employee's Motivation Scale", Tran Kim Dung and Nguyen Ngoc Lan Vy (2011) developed a framework for researching and testing factors through the survey of full-time employees in Ho Chi Minh city. Based on this research, Nguyen Thi Phuong Dung (2012) also had a paper "Building scales to motivate office workers in Can Tho city". Besides that, there are some other researches such as "Developing the framework for motivation in public sector in Vietnam" by Hoang Thi Hong Loc and Nguyen Quoc Nghi (2014) and research "Factors affecting motivation of employees in foreign invested enterprises in Dong Nai" by Nguyen Van Hiep and Nguyen Thi Quynh (2014).

Ho Chi Minh City is the economic center of Vietnam. The existence and development of businesses in Ho Chi Minh City will not only contribute to the socio-economic development of Ho Chi Minh City, but also contribute to the general socio-economic development of Vietnam. One of the factors contributing to the success of businesses in this city is the office workers. Therefore, businesses need to consider what factors affecting the motivation of office workers and find solutions to create and enhance motivation for office workers in Ho Chi Minh City. For these above mentioned reasons, the study "Factors affecting work motivation of office workers in Ho Chi Minh City, Vietnam" is extremely crucial.

To achieve this aim, the authors applied the quantitative and qualitative approach. The independent variables regarding factors affecting work motivation of office workers in Ho Chi Minh City. The following section presents a review of the literature, the proposed research model with eight hypotheses and a description of the methodology employed to address the research problems and test the hypotheses. The result section incorporates the respondents' characteristics, assessment of the reliability and validity of the study scales. From the findings, the authors present some recommendations for managers in Ho Chi Minh City businesses. Finally, the conclusion section is provided, which summarizes results of the study and shows limitations of the study. 


\section{Theoretical basis}

\section{A. Concept of motivation}

There are variations of definitions to describe the concept of motivation. Herzberg (1959) states that "motivation is the desire and willingness of employees to exert high efforts toward organization's goals". Motivation is defined by Robbins (1993) as the willingness to exert high level of effort toward organizational goals, conditioned by the effort's ability to satisfy some individual need. According to Greenberg J and Baron (2003), the concept of motivation is divided into three main parts. The first part focuses on arousal that deals with the drive, or energy behind individual's action. People tend to be guided by their interest in making a good impression on others, doing interesting work and being successful in what they do. The second part refers to the choice people make and the direction their behavior takes. The last part deals with maintaining behavior, clearly defining how long people have to persist at attempting to meet their goals. According to Mitchell (1982), motivation is "all psychological processes that generate the initiation, direction and persistence of voluntary actions aiming to achieve objectives". By incorporating the definitions of Vroom (1964), Steers \& Porter (1981), Locke, Shaw, Saari \& Latham (1981), Jones (1995), Pinder (1998) stated the concept of motivation as follows: "Work motivation is a set of energetic forces that originates both within as well as beyond an individual's being, to initiate work - related behavior and to determine its form, direction, intensity and duration".

Many Vietnamese scholars have proposed various definitions of motivation. Bui Anh Tuan, Pham Thuy Huong (1998) stated that "Labor motivation is the internal factor that motivates people to work in conditions that allow for productivity and high efficiency. Expression of motivation is the willingness, effort and passion to work towards achieving the goals of the organization as well as the employees themselves". Nguyen Van Diem and Nguyen Ngoc Quan (2007) argued that "motivation is the workers' desire and willingness to make an effort in order to achieve the organizational goals". Motivation is also influenced by many factors. They are divided into three basic types: Type one: factors that are intrinsic to human nature such as human interests, personal goals, personal attitudes, personal ability and capacity, seniority, work experience. Type two: environmental factors are external factors that affect employees such as the business culture, the human resource policies. Type three: the nature of work is the key factor affecting salary of employees in the organizations such as: stability and autonomy of job, variation in responsibility and duty, complexity of work, attractive and interesting work (Nguyen Van Diem, Nguyen Ngoc Quan, 2007). In common with Herzberg (1959), Nguyen Van Diem and Nguyen Ngoc Quan (2007), the concept of motivation in this paper is defined as the willingness of employees to increase efforts towards meeting the goals of the organization.

\section{B. Factors affecting motivation}

There are different factors affecting work motivation depending on the purposes of studies. Compiled from the theories and research results of Hersey \& Blanchard (1946), Kenneth A. Kovach (1987) presented a ten-factor model that influences the motivation of employees. These include: interesting work, full appreciation of work done, feelings of being in on things, job security, good wages, promotion and growth in organization, good working conditions, personal loyalty to employees, tactful discipline, sympathetic help with personal problems. In particular, the factor of work interest is the most influential factor in the motivation of employees.

Research results from Re'em (2010) showed that at least 14 motivational factors to encourage employees to work better. These factors consist of rewarding, recognition, feedback, relatedness/commitment, responsibility/autonomy, achievement/challenge/goal setting, growth- 
career advancement, growth-training, interesting work, important work, participation, interpersonal relationships, working environment, fairness, work-life-balance. Along with these 14 factors are 46 specific tactics that fit the content of each factor. For example, managers must learn their employees' characters before giving them more freedom. Young employees are usually motivated by receiving responsibility. Therefore, when granting responsibility, managers should clearly distinguish between their role and the role of the employee. Managers should define only the "what" to do and let the employee decide on the "how". On the other hand, because motivation is the issue of each individual, tactics should be used with caution and be appropriately applied for each situation and individual.

In Vietnam, there are also many research papers on the motivation of employees, especially the office workers. Typically, Tran Kim Dung and Nguyen Ngoc Lan Vy (2011) argued that the motivation of employees was influenced by four main factors: suitable work, reasonable policies and regimes (compensation, welfare, promotion), good relationship in work and company brand. In particular, the element of the benefit policy has the strongest impact on the motivation of employees. Nguyen Thi Phuong Dung (2012) conducted a study on motivation of office workers in Can Tho City and the results showed that motivation of employees is influenced by four factors: organizational regulations and policies, working relations, interesting work and social welfare. The characteristics of office workers are working in administrative hours, so interesting work, salary, bonus and welfare policy are considered as important factors.

\section{Proposed research model}

Based on the research model of Kenneth A. Kovach, combining with the characteristics of work culture and office environment in Vietnam, the authors have built a scale of eight factors affecting work motivation of office workers in Ho Chi Minh City, Vietnam shown in Figure 1.

Figure 1: The proposed model

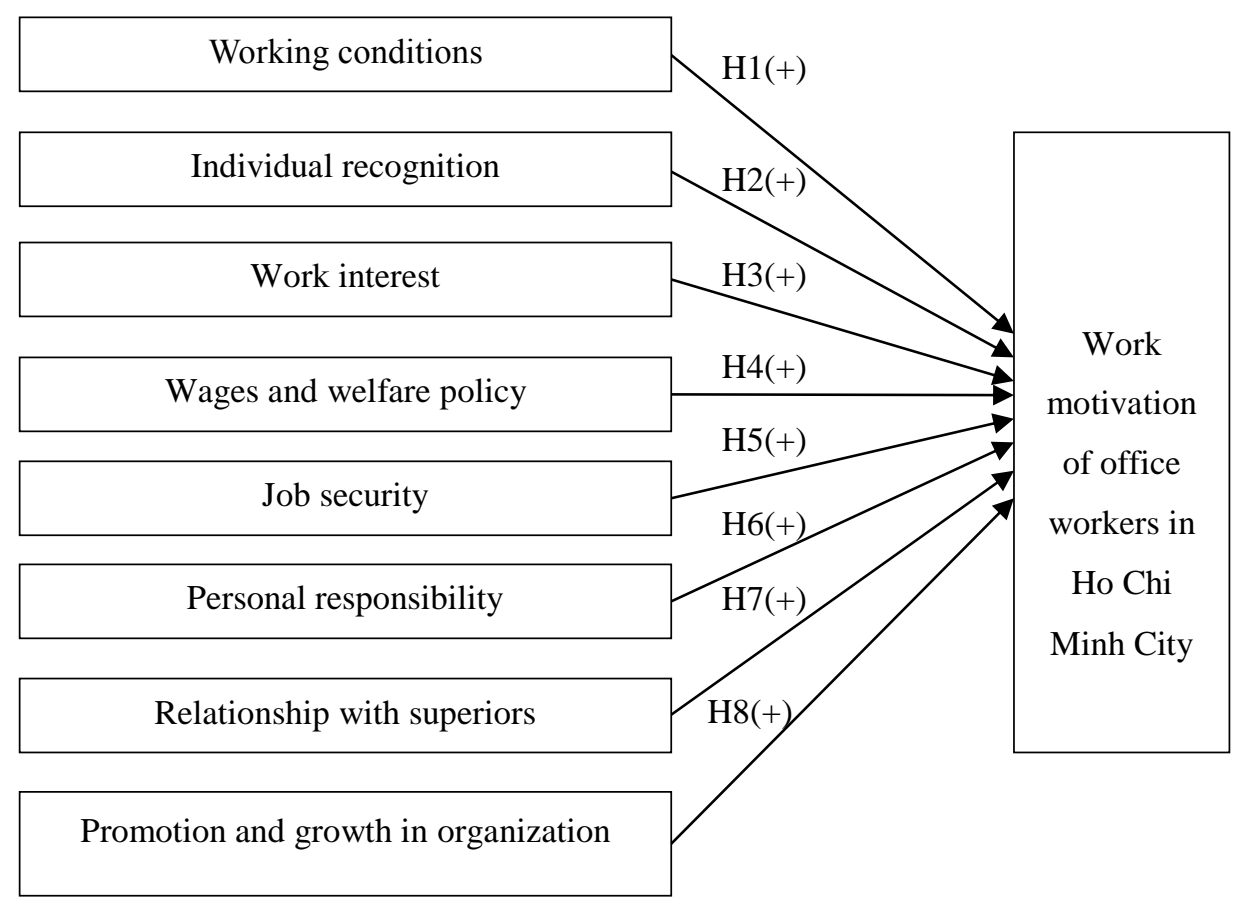

Source: Proposed by authors 
The research hypotheses are proposed as follows:

- Hypothesis 1: Working conditions have positive effect on work motivation of office workers in Ho Chi Minh City

- Hypothesis 2: Individual recognition has positive effect on work motivation of office workers in Ho Chi Minh City

- Hypothesis 3: Work interest has positive effect on work motivation of office workers in Ho Chi Minh City

- Hypothesis 4: Wages and welfare policy has positive effect on work motivation of office workers in Ho Chi Minh City

- Hypothesis 5: Job security has positive effect on work motivation of office workers in Ho Chi Minh City

- Hypothesis 6: Personal responsibility has positive effect on work motivation of office workers in Ho Chi Minh City

- Hypothesis 7: Relationship with superisors has positive effect on work motivation of office workers in Ho Chi Minh City

- Hypothesis 8: Promotion and growth in organization have positive impact on work motivation of office workers in Ho Chi Minh City

\section{Methodology}

To achieve the research objective, the quantitative and qualitative approach was applied. Qualitative research is used to study and analyze theories and factors affecting work motivation. Quantitative research is used to test the scale and assess the factors influencing the motivation of office workers in Ho Chi Minh City, Vietnam. The study was conducted in two main phases: preliminary research with the sample size of 50 respondents and official research with the sample size of 330 respondents. Nominal scale, interval scale and ordinal scale with 5 levels of Likert are used in this study. The data were processed by SPSS version 21. Cronbach's Alpha and Exploratory factor analysis (EFA) are used to test the validity of the scale, linear analysis is used to test the factors that affect work motivation of office worker.

In terms of data source, primary and secondary data are used. Secondary sources are collected through studies, researches, journal articles, books by both domestic as well as international researchers. Primary sources are collected by conducting survey directly or indirectly via internet. 
Table 1. Concepts' scales

\begin{tabular}{|c|c|c|}
\hline Factors & Items & Content \\
\hline \multirow{4}{*}{$\begin{array}{l}\text { Working } \\
\text { conditions }\end{array}$} & DKLV1 & Relaxing time and space \\
\hline & DKLV2 & Safe working environment \\
\hline & DKLV3 & Well-equipped working environment \\
\hline & DKLV4 & Supportive colleagues \\
\hline \multirow{5}{*}{$\begin{array}{l}\text { Individual } \\
\text { recognition }\end{array}$} & CN1 & Be asked before making decisions \\
\hline & $\mathrm{CN} 2$ & Achievements are recognized \\
\hline & CN3 & Bonus of mission completion \\
\hline & CN4 & Personal contribution contributes to promotion \\
\hline & CN5 & Superiors and colleagues appreciate talent and contribution \\
\hline \multirow{4}{*}{ Work interest } & HT1 & Challenging job \\
\hline & HT2 & Job fits competence \\
\hline & HT3 & Job fits personal orientation \\
\hline & HT4 & Job helps self-perfection \\
\hline \multirow{5}{*}{$\begin{array}{l}\text { Wages and } \\
\text { welfare policy }\end{array}$} & LUONG1 & Competitive salary \\
\hline & LUONG2 & Satisfactory salary and reward \\
\hline & LUONG3 & Fair and transparent salary policy \\
\hline & LUONG4 & Adequate insurance policy \\
\hline & LUONG5 & Suitable allowances \\
\hline \multirow{4}{*}{$\begin{array}{l}\text { Personal } \\
\text { responsibility }\end{array}$} & TN1 & Responsibility without affecting freedom \\
\hline & TN2 & Voluntary to comply with organization's regulation \\
\hline & TN3 & Voluntary to fulfil assigned tasks \\
\hline & TN4 & Voluntary to follow vision, mission of organization \\
\hline \multirow{4}{*}{$\begin{array}{l}\text { Relationship } \\
\text { with superiors }\end{array}$} & CT1 & Excellent and reliable superiors \\
\hline & $\mathrm{CT} 2$ & Fair and friendly superiors \\
\hline & CT3 & Achievement can be improved with the support of superiors \\
\hline & CT4 & Good relationship with superiors \\
\hline \multirow{6}{*}{$\begin{array}{l}\text { Promotion and } \\
\text { growth in } \\
\text { organization }\end{array}$} & TT1 & Learnt knowledge can be applied \\
\hline & TT2 & Have opportunities to improve skills \\
\hline & TT3 & Can learn from job \\
\hline & TT4 & Permanent employees' training \\
\hline & TT5 & $\begin{array}{l}\text { Create promotion opportunities for employees having } \\
\text { competence and contribution }\end{array}$ \\
\hline & TT6 & Fair and transparent promotion policy \\
\hline
\end{tabular}

\section{Results}

\section{A. Characteristics of the respondents}

In terms of gender, the findings indicate that the respondents comprised of $43.6 \%$ male and $56.4 \%$ female respectively. The difference between male and female is not much because the authors conducted non-propability sampling, so respondents in the survey equally distributed in both sexes.

Regarding age, the findings show that 176 respondents are under the age of 25 (53.3\%), 152 respondents are from 25 to under 50 years old (46.1\%) and 2 respondents are over 50 years old $(0.6 \%)$. 
As collecting samples through the Internet, this result accurately reflects the current user structure. Respondents less than 25 years old often spend more time using social networking sites and other Internet services, accounting for the highest proportion among the three age groups. At the same time, respondents from 25 to under 50 also regularly use the Internet for entertainment needs as well as for work.

In terms of education level, the statistics on the educational level of the respondents show that $89.4 \%$ of the respondents have completed or completed the tertiary educational program; $8.2 \%$ of the respondents have had college degree. In addition, $2.4 \%$ of the respondents completed or have completed higher educational programs. This is also an advantage of the study when it can generalize all basic education level of office workers. The results reflect the current situation, office workers with university and college degrees account for the large proportion. At the same time, as the demand for recruiting is higher, employees with higher education level is understandable.

Regarding working experience, because the research respondents are office workers in Ho Chi Minh City - dynamic city with many job opportunities for young people, the difference in working experience is noticeable with 8 respondents having more than five years' experience, 108 respondents with three and less than five years' experience. At the same time, there are 214 respondents with less than three years' experience, accounting for $64.8 \%$.

Regarding income, according to the survey results, the group of people with income below 10 million VND is the largest with 218 respondents. At the same time, the respondents with income from 10 to less than 20 million VND are only 99 while there are 13 respondents from 20 million VND or more. Most of respondents tend to earn less than 10 million VND per month because most of them have less than three years of experience. The number of respondents in the other two segments also tends to correlate with the work experience.

\section{B. Results}

The first Cronbach's Alpha test results showed that the "Job security" variable had a coefficient of confidence of $0.572<0.7$, so this variable was excluded from the study. At the same time, in the factor of "Individual recognition", the original Cronbach Alpha coefficient of the CN5 variable - superiors and colleagues appreciate talents and contributions of employee was 0.834 , after eliminating the first item in the scale, the index increased significantly to 0.846 . Thus, CN5 variable was decided to remove from the survey to increase the reliability of the scale.

After cleaning and re-testing data, the coefficients of total correction of factors were greater than 0.4 and Cronbach's Alpha coefficients were greater than 0.7 and no trash variable was observed. After deleting inappropriate variable, 31 variables were remained, followed by 7 variable groups and 4 dependent variables belonging to the "Working motivation". The results are recorded in Table 2. 
Table 2. Cronbach's Alpha coefficient results

\begin{tabular}{|c|c|c|c|c|c|}
\hline Item & $\begin{array}{c}\text { Corrected } \\
\text { item - Total } \\
\text { correlation }\end{array}$ & $\begin{array}{c}\text { Cronbach's } \\
\text { Alpha if item } \\
\text { deleted }\end{array}$ & Item & $\begin{array}{c}\text { Corrected item } \\
\text { - Total } \\
\text { Correlation }\end{array}$ & $\begin{array}{c}\text { Cronbach's } \\
\text { Alpha if item } \\
\text { deleted }\end{array}$ \\
\hline \multicolumn{3}{|c|}{ Working conditions } & \multicolumn{3}{|c|}{ Wages and welfare policy } \\
\hline \multicolumn{3}{|c|}{ Cronbach's Alpha $=0.873$} & \multicolumn{3}{|c|}{ Cronbach's Alpha $=0.924$} \\
\hline DKLV1 & 0.733 & 0.837 & LUONG1 & 0.819 & 0.904 \\
\hline DKLV2 & 0.699 & 0.849 & LUONG2 & 0.762 & 0.915 \\
\hline DKLV3 & 0.728 & 0.838 & LUONG3 & 0.826 & 0.902 \\
\hline DKLV4 & 0.757 & 0.826 & LUONG4 & 0.752 & 0.916 \\
\hline \multicolumn{3}{|c|}{ Individual recognition } & LUONG5 & 0.853 & 0.896 \\
\hline \multicolumn{3}{|c|}{ Cronbach's Alpha $=0.846$} & \multicolumn{3}{|c|}{ Personal responsibility } \\
\hline CN1 & 0.636 & 0.825 & \multicolumn{3}{|c|}{ Cronbach's Alpha $=0.837$} \\
\hline $\mathrm{CN} 2$ & 0.725 & 0.786 & TN1 & 0.737 & 0.764 \\
\hline CN3 & 0.673 & 0.809 & TN2 & 0.636 & 0.808 \\
\hline CN4 & 0.700 & 0.798 & TN3 & 0.642 & 0.806 \\
\hline \multicolumn{3}{|c|}{ Work interest } & TN4 & 0.663 & 0.797 \\
\hline \multicolumn{3}{|c|}{ Cronbach's Alpha $=0.881$} & \multicolumn{3}{|c|}{ Relationship with superiors } \\
\hline HT1 & 0.711 & 0.860 & \multicolumn{3}{|c|}{ Cronbach's Alpha = 0.865} \\
\hline HT2 & 0.767 & 0.838 & CT1 & 0.713 & 0.828 \\
\hline HT3 & 0.786 & 0.831 & CT2 & 0.677 & 0.844 \\
\hline HT4 & 0.707 & 0.862 & CT3 & 0.745 & 0.815 \\
\hline \multicolumn{3}{|c|}{ Promotion and growth in organization } & CT4 & 0.727 & 0.824 \\
\hline \multicolumn{3}{|c|}{ Cronbach's Alpha = 0.932} & \multicolumn{3}{|c|}{ Work motivation } \\
\hline TT1 & 0.749 & 0.926 & \multicolumn{3}{|c|}{ Cronbach's Alpha $=0.924$} \\
\hline TT2 & 0.784 & 0.922 & DLLV1 & 0.798 & 0.909 \\
\hline TT3 & 0.854 & 0.913 & DLLV2 & 0.818 & 0.903 \\
\hline TT4 & 0.856 & 0.912 & DLLV3 & 0.810 & 0.906 \\
\hline TT5 & 0.811 & 0.918 & DLLV4 & 0.873 & 0.884 \\
\hline TT6 & 0.758 & 0.926 & & & \\
\hline
\end{tabular}

The EFA was conducted to test the validity of the measurement of seven independent variables that met the requirements of Cronbach's Alpha reliability testing. The results of the EFA test with the KMO coefficient $=0.889$, Sig value of Barlett test $=0.000$, the Total variance explained with $73.368 \%$ showed that the data are consistent with the research model. 
Table 3. Factor rotation matrix result of independent variables

\begin{tabular}{|c|c|c|c|c|c|c|c|}
\hline & \multicolumn{7}{|c|}{ Factors } \\
\hline & 1 & 2 & 3 & 4 & 5 & 6 & 7 \\
\hline TT4 & .866 & & & & & & \\
\hline TT3 & .858 & & & & & & \\
\hline TT2 & .804 & & & & & & \\
\hline TT5 & .787 & & & & & & \\
\hline TT6 & .778 & & & & & & \\
\hline TT1 & .772 & & & & & & \\
\hline LUONG5 & & 869 & & & & & \\
\hline LUONG3 & & .849 & & & & & \\
\hline LUONG1 & & .832 & & & & & \\
\hline LUONG2 & & .776 & & & & & \\
\hline LUONG4 & & .772 & & & & & \\
\hline DKLV1 & & & .805 & & & & \\
\hline DKLV4 & & & 798 & & & & \\
\hline DKLV3 & & & .784 & & & & \\
\hline DKLV2 & & & .759 & & & & \\
\hline CT4 & & & & .848 & & & \\
\hline CT1 & & & & .841 & & & \\
\hline CT3 & & & & .815 & & & \\
\hline CT2 & & & & .804 & & & \\
\hline CN2 & & & & & .800 & & \\
\hline CN4 & & & & & .782 & & \\
\hline CN1 & & & & & .761 & & \\
\hline CN3 & & & & & .752 & & \\
\hline $\mathrm{HT} 2$ & & & & & & .802 & \\
\hline HT3 & & & & & & .774 & \\
\hline HT4 & & & & & & .751 & \\
\hline HT1 & & & & & & .729 & \\
\hline TN1 & & & & & & & .867 \\
\hline TN4 & & & & & & & .811 \\
\hline TN3 & & & & & & & .799 \\
\hline TN2 & & & & & & & .794 \\
\hline $\begin{array}{c}\text { Initial eigenvalues } \\
\text { (total) }\end{array}$ & 9.669 & 3.106 & 2.755 & 2.317 & 1.794 & 1.757 & 1.346 \\
\hline $\begin{array}{c}\text { Total variance } \\
\text { explained - } \\
\text { cummulative (\%) }\end{array}$ & 31.190 & 41.210 & 50.097 & 57.572 & 63.359 & 69.025 & 73.368 \\
\hline
\end{tabular}


Table 4. Model summary

\begin{tabular}{|c|c|c|c|c|c|}
\hline Model & R & R2 & Adjusted R2 & $\begin{array}{c}\text { Std. Error of } \\
\text { the Estimate }\end{array}$ & $\begin{array}{c}\text { Durbin - } \\
\text { Waston }\end{array}$ \\
\hline 1 & 0.821 & 0.674 & 0.667 & 0.523 & 1.961 \\
\hline
\end{tabular}

The results show that the relevance of the research model is $67.4 \%$, or $67.4 \%$ variance of work motivation is explained by 7 independent variables in the model while the remaining $32 \%$ is due to other variables and random error.

Table 5. Coefficients

\begin{tabular}{|c|c|c|c|c|c|c|c|}
\hline \multirow{3}{*}{ Model } & \multirow{2}{*}{\multicolumn{2}{|c|}{$\begin{array}{l}\text { Unstandardized } \\
\text { Coefficients }\end{array}$}} & \multirow{3}{*}{$\begin{array}{c}\begin{array}{c}\text { Standardized } \\
\text { Coefficients }\end{array} \\
\text { Beta }\end{array}$} & \multirow{3}{*}{$\mathbf{T}$} & \multirow{3}{*}{ Sig. } & \multicolumn{2}{|c|}{ Collinearity statistics } \\
\hline & & & & & & \multirow{2}{*}{ Tolerance } & \multirow{2}{*}{ VIF } \\
\hline & B & Std. Error & & & & & \\
\hline Const & -0.916 & 0.212 & & -4.325 & 0.000 & & \\
\hline DKLV & 0.91 & 0.038 & 0.093 & 2.406 & 0.017 & 0.670 & 1.492 \\
\hline $\mathrm{CN}$ & 0.283 & 0.038 & 0.282 & 7.379 & 0.000 & 0.691 & 1.446 \\
\hline HT & 0.145 & 0.049 & 0.124 & 2.964 & 0.003 & 0.579 & 1.728 \\
\hline LUONG & 0.166 & 0.041 & 0.158 & 4.045 & 0.000 & 0.666 & 1.501 \\
\hline TN & 0.087 & 0.036 & 0.077 & 2.407 & 0.017 & 0.986 & 1.014 \\
\hline $\mathrm{CT}$ & 0.288 & 0.028 & 0.352 & 10.261 & 0.000 & 0.861 & 1.161 \\
\hline TT & 0.210 & 0.041 & 0.205 & 5.101 & 0.000 & 0.624 & 1.602 \\
\hline
\end{tabular}

The research findings showed that work motivation of office workers is affected by seven factors: relationship with superiors, individual recognition, promotion and growth in organization, wages and welfare policy, work interest, working conditions, personal responsibility. The degree of impact of each factor depends on the Beta coefficient, the larger the coefficient is, the greater the impact level is and vice versa. The regression model is as follows:

$$
\begin{aligned}
\text { Motivation }=-0.916+0.093 \mathrm{DKLV}+ & 0.282 \mathrm{CN}+0.124 \mathrm{HT}+0.158 \text { Luong }+0.077 \mathrm{TN}+0.352 \mathrm{CT} \\
& +0.205 \mathrm{TT}
\end{aligned}
$$

Specifically, the factor Relationship with superiors has the greatest impact with $\beta=0.352$; followed by individual recognition with $\beta=0.282$; Promotion and growth in organization with $\beta=$ 0.205; Wages and welfare policies with $\beta=0.158$; Work interest with $\beta=0.124$; Working conditions with $\beta=0.093$; Individual responsibility with $\beta=0.077$.

\section{Conclusion and discussion}

Based on the study results, in order to create and enhance work motivation for office workers in Ho Chi Minh City, some recommendations are proposed as follows:

First, strengthen the relationship between superiors and office workers.

Study results show that relationships with superiors are the most influential factor in the motivation of office workers. According to the scale components, having good superiors who care and support employees to improve performance is what office workers, especially young staff expect most. Therefore, in addition to the continuous development of professional skills, managers should establish relationships with subordinates to motivate and support them to achieve the favorable results for the 
whole organization. At the same time, it is essential that all employees should be treated fairly and equally in the businesses.

Second, recognize the contribution of individuals

Study results show that individual recognition is one of the factors influencing the motivation of office workers. This is quite understandable because office workers, especially young people always want to be recognized for their achievements on the job. Therefore, managers need to understand this factor to create motivation for employees by recognizing employees' contributions in all forms, whether rewarding or commending, increasing salary or creating career development opportunities.

Third, provide opportunities of promotion and career development for employees

When employees join an organization, they not only want to earn more income, but also want to be well-equipped with professional knowledge, orientation to career path, the title and social status. Therefore, managers should build a road map for employees' career development. When feasible, managers can support employees by allowing them to pursue further education or special training. This not only motivates employees, but also helps the company to build strong management team, contributing to the sustainable development of businesses in the future.

Fourth, develop a reasonable welfare policy

According to the study results, the salary and welfare policy also has positive impact on motivation of office workers. The physical need of a person is indispensable, which means that meeting such need is a prerequisite for employees to dedicate themselves to good work. Therefore, managers should develop a specific salary and benefit framework, describing full benefits at each level. In particular, there should be a clear distinction in terms of work capacity and development potential in order to develop appropriate salary and welfare policies and to consider career advancement opportunities for employees.

In addition to these recommendations, managers also need to focus on factors such as working conditions, work interest, work responsibilities because of their importance in contributing to creating and enhancing work motivation for employees. Typically, managers should create an open work environment, employees automatically learn from each other as well as create a culture of sharing and suggestions in the organizations. When assigning tasks, managers should pay attention to employees' capacity to delegate suitable and challenging tasks.

Because of the importance of human resources to the success of businesses, especially office workers - the key resources in organizations in Ho Chi Minh City, the authors selected the study "Factors affecting work motivation of office workers in Ho Chi Minh City, Vietnam". Based on the motivation theory relating to factors influencing the motivation of employees, a survey was conducted with 330 respondents. The study results show that seven factors: relationship with superiors, individual recognition, promotion and growth in organization, wages and welfare policy, work interest, working conditions, personal responsibility. The authors also proposed some solutions to create and enhance the motivation of office workers in Ho Chi Minh City as follows: manager-office worker relationship reinforcement, individual contribution's recognition; opportunities for promotion and career development; reasonable welfare policies.

However, there are still some certain limitations which are expected to be improved in the future research. First, due to the constraints of time and budget, the sample is relatively small with a limited number of respondents working in Ho Chi Minh City, Vietnam. This definitely limits the level to which the results can be generalized. Second, there are other possible factors that may affect work motivation of office workers in Ho Chi Minh City such as training opportunities to the employees, job placements, status or job title. 


\section{References}

[1] Bui Anh Tuan, Pham Thuy Huong. (2013). Organizational behavior. National Economics University Publisher.

[2] Bui Thi Minh Thu, Le Nguyen Doan Khoi. (2014). Factors affecting the motivation of direct production employees in Vietnam Assembly Corporation. Can Tho University Scientific Journal, 35, 66-78

[3] Greenberg, J., \& Baron, R. A. (2003). Behavior in organizations: Understanding and managing the human side of work. Pearson College Division.

[4] Herzberg. F, Mausner. B, Snyderman. B. (1959). The motivation to work (2nd ed.). Oxford, England: John Wiley.

[5] Kovach. K. A. (1987). What motivates employees? Workers and supervisors give different answers. Business Horizons, 30(5), 58-65.

[6] Hoang Thi Hong Loc, Nguyen Quoc Nghi. (2014). Developing the framework for motivation in public sector in Vietnam. Can Tho University Scientific Journal, 32, 97-105.

[7] Mitchell T. (1982). Motivation: New Direction for Theory, Research and Practice. Academy of Management Review, 7(1), 80-88.

[8] Nguyen Thi Phuong Dung. (2012). Building scales to motivate office workers in Can Tho city. Can Tho University Scientific Journal, 22b, 145-154.

[9] Nguyen Van Hiep, Nguyen Thi Quynh. (2014). Factors affecting motivation of employees in foreign invested enterprises in Dong Nai. Lac Hong Scientific Journal, 1(1), 12-19.

[10] Nguyen Van Diem, Nguyen Ngoc Quan. (2007). Human Resource Management. Hanoi: National Economics University Publishing House.

[11] Pinder CC. (1998). Work Motivation in Organizational Behavior. Upper Saddle River, NJ: Prentice Hall.

[12] Re'em. Y. (2010). Motivating Public Sector Employees: An Application-Oriented Analysis of Possibilities and Practical Tools. Hertie School of Governance, Berlin.

[13] Robbins. (1993). S, Organizational Behavior (6th ed.). Englewood Cliffs, NJ: Prentice Hall.

[14] Tran Kim Dung, Nguyen Ngoc Lan Vy. (2011). Employee's Motivation Scale. Journal of Economic Development, 244. 